\title{
Antismoking Mass Media Campaigns and Support for Smoke-Free Environments, Mobile County, Alabama, 2011-2012
}

\author{
Gabriel H. Fosson, MPA; Debra M. McCallum, PhD; Michael B. Conaway, JD
}

\begin{abstract}
Suggested citation for this article: Fosson GH, McCallum DM, Conaway MB. Antismoking Mass Media Campaigns and Support for Smoke-Free Environments, Mobile County, Alabama, 2011-2012. Prev Chronic Dis 2014;11:140106. DOI: http:// dx.doi.org/10.5888/pcd11.140106.
\end{abstract}

\section{PEER REVIEWED}

\section{Abstract}

\section{Introduction}

In 2011, the Mobile County Health Department began a 12-month antismoking educational media campaign to educate citizens on the dangers of secondhand smoke. The campaign overlapped with the Centers for Disease Control and Prevention's 3-month national antismoking Tips from Former Smokers media campaign. We aimed to evaluate the effect of these campaigns on support for smoke-free environments and knowledge of the dangers of secondhand smoke.

\section{Methods}

Cross-sectional precampaign and postcampaign telephone surveys collected data from a random sample of Mobile County adults in the summers of 2011 and 2012. Outcome measures included changes in support for smoke-free environments and knowledge of the dangers of secondhand smoke. The participation rate among the households that were successfully reached was $45 \%$ in 2011 and $44 \%$ in 2012.

\section{Results}

On the postcampaign survey, $80.9 \%$ of respondents reported seeing a television advertisement, $29.9 \%$ reported hearing a radio advertisement, and $49.0 \%$ reported seeing a billboard. Overall, support for smoke-free bars increased significantly after the intervention $(38.1 \%$ to $43.8 \% ; P=.01)$ but not for workplaces or restaur- ants. Self-reported exposure to the media campaign was associated with higher levels of support for smoke-free workplaces, restaurants, and bars.

\section{Conclusion}

Educational mass media campaigns have the potential to increase support for smoke-free protections and may increase knowledge about the dangers of secondhand smoke among certain populations.

\section{Introduction}

Educational mass media campaigns against smoking can be an effective means of changing attitudes (1-3) and behaviors (4-8) related to tobacco use. Media campaigns have the potential to change social perceptions of smoking $(1,2)$ and knowledge about the dangers of secondhand smoke (SHS) (2) and thus may increase support for smoke-free environments. However, research on the effect of educational media campaigns on desire for smokefree protections is limited. Two such studies have been conducted within the past 5 years in Mexico City, Mexico, and in São Paulo, Brazil, evaluating the effects of media campaigns on support for recently protected smoke-free environments. Results from both studies concluded that exposure to the media messages was positively associated with increased support for the new smoke-free protections $(9,10)$. We investigated the effect of an educational media campaign on support for smoke-free environments before the implementation of smoke-free protections.

In 2010, Mobile County, Alabama, home to 413,000 residents, had a higher prevalence of smoking $(25.0 \%)$ than the national average $(17.3 \%)(11,12)$, and only 2 of its 12 municipalities had adopted legislation restricting smoking in indoor public places. Without a state law restricting smoking in indoor public places, municipalities in Alabama are required to enact local legislation to protect residents from SHS. Mobile County was selected in 2010 by the Centers for Disease Control and Prevention (CDC) to participate in the Communities Putting Prevention to Work (CPPW) initiat- 
ive. The purpose of the national CPPW program was to reduce chronic disease associated with tobacco use or obesity through sustainable, high-impact change in systems and environments (13). The Mobile CPPW program used an antitobacco educational media campaign as one of its evidence-based interventions to help educate residents about the dangers of tobacco use and SHS exposure.

The objective of our evaluation was to assess the reach and potential effects of the Mobile County Just Breathe Smoke Free (Just Breathe) educational media campaign and CDC's Tips from a Former Smoker (Tips) national antismoking media campaign on residents' attitudes toward smoke-free environments and knowledge about the dangers of SHS.

\section{Methods}

\section{Media campaign}

The Mobile County Health Department (MCHD) contracted with Lewis Communications to manage and assist in developing the Just Breathe educational media campaign. The campaign included television, radio, print, billboard, and online advertisements. MCHD produced an upbeat, animated television advertisement based on focus group research for this campaign and ran 3 additional television advertisements borrowed from previous campaigns that focused on the dangers of SHS. Additionally, MCHD ran 2 radio, 8 print, and 3 billboard advertisements.

From September 26, 2011, to September 30, 2012, the campaign placed the following paid advertisements: 1,700 television spots, 2,100 cable spots, 8,500 radio spots, and 200 print insertions in local newspapers and magazines. Billboard advertisements were placed between September 26, 2011, and August 31, 2012, with a daily effective circulation (the average number of adults 18 or older passing and potentially exposed to an advertisement each day) of 488,000. Paid online advertising was placed between September 26, 2011, and December 12, 2011, as follows: 14.2 million total impressions (the number of times an advertisement is displayed online) on Facebook resulting in 1,900 clicks and 6.3 million impressions on AL.com resulting in 6,800 clicks. The campaign also received earned media exposure, including editorials, news stories, and public service announcements, which added unpaid advertising in each media outlet.

CDC's Tips campaign overlapped with the Just Breathe campaign. The Tips campaign lasted for 12 weeks, starting on March 19, 2012, and included television, radio, print, billboard, and website advertisements. In contrast to the Just Breathe campaign, the Tips campaign used hard-hitting, emotional advertisements, which depicted suffering caused by smoking. An evaluation of the Tips campaign found that it was effective at increasing population-level quit attempts (14).

\section{Survey methods}

A precampaign-postcampaign cross-sectional telephone survey was conducted by The University of Alabama to assess the effects of the educational media campaigns. Researchers at the university developed and pilot-tested survey questions to evaluate exposure to the educational media campaign and support for smoke-free policies. Questions regarding tobacco use, knowledge of the dangers of SHS, and awareness of the quitline were taken from previously validated surveys (15), including CDC's Behavioral Risk Factor Surveillance System and Adult Tobacco Survey and previous tobacco studies conducted by the university. The baseline survey was conducted between August 8 and October 1, 2011, ending 6 days after paid advertising of the Just Breathe campaign began. The postcampaign survey occurred during the last several months of the educational media campaign from June 9 through September 5, 2012. This study was approved by the institutional review board at The University of Alabama and by the Alabama Department of Public Health.

Data collection for the study was conducted by the Capstone Poll at The University of Alabama. Random-digit dialing was used to select households in Mobile County, and in each household a respondent was randomly selected for participation. Mobile County residents aged 19 years or older were eligible to participate in the study. By using the American Association for Public Opinion Research's response rate 1 formula (16), the participation rate in 2011 was $21.9 \%$, based on 845 completions and 3,861 households, and in 2012 was $22.6 \%$, based on 766 completions and 3,396 households. Approximately 52\% (2011) and 49\% (2012) of the telephone numbers provided were never reached after multiple attempts. Among the households that were reached, the cooperation rate was $45 \%$ in 2011 and $44 \%$ in 2012 .

\section{Measures}

Exposure to antitobacco media messages was assessed in the precampaign and postcampaign surveys using 4 questions, which asked whether participants had seen advertisements about the dangers of smoking in different media outlets: television, radio, billboard, and newspaper or other print media. In the postcampaign survey, an open-ended follow-up question after the television and radio exposure questions helped identify recalled advertisements associated with the Just Breathe or Tips campaigns. Open-ended information was not solicited about the print advertisements. Interviewers were trained to recognize 11 television ad-

\footnotetext{
The opinions expressed by authors contributing to this journal do not necessarily reflect the opinions of the U.S. Department of Health and Human Services, the Public Health Service, the Centers for Disease Control and Prevention, or the authors' affiliated institutions.
} 
vertisements (4 Just Breathe, 7 Tips) and 9 radio advertisements (2 Just Breathe, 7 Tips), coding the open-ended responses using computer-assisted telephone interviewing software during the interview.

Respondents were asked 4 questions in both precampaign and postcampaign surveys to gauge attitudes toward smoke-free policies in workplaces, restaurants, and bars and a comprehensive policy for all public indoor areas. Knowledge about the dangers of SHS was assessed using 6 questions that came from CDC's Adult Tobacco Survey. Participants were asked to rate the overall harmfulness of SHS to health and indicate whether breathing SHS causes lung cancer in adults, heart disease in adults, colon cancer in adults, respiratory problems in children, and sudden infant death syndrome.

\section{Statistical methods}

Poststratification weights were calculated by raking along dimensions of age, sex, race, and education, using census-based proportions to correct for the underrepresentation or overrepresentation of demographic subgroups in the data. Descriptive statistics and binary logistic regression analyses were conducted using SPSS software version 20 (IBM Inc). Yates $\chi^{2}$ tests of significance, corrected for continuity and for multiple comparisons (using HolmBonferroni) (17) were used to compare categorical survey responses between the precampaign and postcampaign surveys and to compare the demographic characteristics. Multivariate logistic regression was used to evaluate the effect of media exposure on support for smoke-free environments and knowledge about the dangers of SHS while controlling for smoking status, sex, race, and education level. For the regression analysis, media exposure was defined by whether respondents were able to describe 1 of the Just Breathe or Tips campaign advertisements unaided. Dichotomous categorical variables were established for questions about support for smoke-free environments and knowledge, with responses that expressed uncertainty such as "it depends" or "don't know" being combined with the "no" responses.

\section{Results}

There were no significant demographic differences between the unweighted precampaign and postcampaign samples (Table 1).

\section{Exposure to the educational media campaign}

On the basis of the weighted 2012 postcampaign survey results, $80.9 \%$ of survey participants reported seeing an advertisement on television, and $29.9 \%$ of participants reported hearing an advertisement on the radio, about the dangers of smoking during the 30 days before the survey. Almost half (49.0\%) of participants repor- ted seeing a billboard, and $23.0 \%$ of participants saw advertisements in print media about the dangers of smoking during the 30 days before the survey (Table 2). Significant differences in self-reported media exposure between black and white residents were found for television advertisements (black, 86.5\%; white, 77.7\%; $P=.03$ ), but not for radio, print, or billboard advertisements.

When asked to describe the television, radio, and billboard advertisements they remembered, $14.1 \%$ of survey respondents described a Just Breathe advertisement (and not a Tips advertisement), 29.6\% described a Tips advertisement (and not a Just Breathe advertisement), and $7.7 \%$ described advertisements from both campaigns. Overall, $51.4 \%$ of respondents were able to describe at least 1 television advertisement from either campaign.

For the radio advertisements, $9.6 \%$ of participants described a Just Breathe radio advertisement and $2.7 \%$ of participants described a Tips radio advertisement. Open-ended descriptions of the billboards suggest that approximately $13 \%$ of all respondents saw a Just Breathe billboard.

Because the Just Breathe paid advertising began 6 days before completion of the precampaign survey, we compared responses of the individuals completing the survey before and after September 25,2011 , for questions regarding media exposure and found no significant differences.

\section{Changes in support and knowledge}

Support for smoke-free bars increased significantly from precampaign to postcampaign (precampaign, $38.1 \%$; postcampaign, $43.8 \% ; P=.01)$. However, there were not significant changes in support for smoke-free workplaces, restaurants, or comprehensive protections for all public indoor areas. Stratified by race, there was a significant increase in support for smoke-free restaurants among black respondents (precampaign $83.2 \%$; postcampaign $89.0 \% ; P=$ .04 ) and for smoke-free bars among white respondents (precampaign, $34.2 \%$; postcampaign, $41.4 \%$; $P=.02$ ) (Table 2 ).

Knowledge of the dangers of SHS increased significantly for only 1 out of 6 measures. Belief that SHS causes heart disease in adults increased from $71.2 \%$ to $78.5 \%(P<.001)$. However, a stratified analysis showed significant differences in changes in knowledge based on racial group and suggests that the increases in knowledge occurred primarily among black respondents with small, nonsignificant increases among white respondents. For black respondents, we found significant increases in 4 of 6 measures: the belief that SHS is very harmful and that SHS causes lung cancer in adults, heart disease in adults, and respiratory problems in children (Table 2). There were no significant increases in knowledge among white respondents.

The opinions expressed by authors contributing to this journal do not necessarily reflect the opinions of the U.S. Department of Health and Human Services, the Public Health Service, the Centers for Disease Control and Prevention, or the authors' affiliated institutions. 


\section{Campaign exposure, support for smoke-free environments, and knowledge}

The multivariate logistic regression analyses showed that exposure to the educational media campaigns was associated with greater support for smoke-free environments (Table 3). Residents who reported exposure to 1 or both of the campaigns were significantly more likely than unexposed residents to support smoke-free workplaces, restaurants, and bars $(P=.01$ for each location). Among the other predictors included in our analysis, we found that nonsmokers were significantly more likely than smokers to support all of the smoke-free environments $(P<.001)$, and that respondents with at least some college education were more likely than those with less than a high school education to support smoke-free workplaces $(P=.001)$ and restaurants $(P=.03)$.

\section{Discussion}

The results of this study offer support for the use of educational media campaigns to broaden support for smoke-free environments and increase knowledge about the dangers of SHS. In assessing the effect of the campaign using logistic regression analyses, we found that those who recalled exposure to the campaign were significantly more likely to support smoke-free workplaces, restaurants, and bars than those who were not exposed. However, in measuring support from precampaign to postcampaign for the full sample, we found an increase in support for only 1 of 4 measures; support for smoke-free bars increased significantly, while support for smoke-free restaurants, smoke-free workplaces, or comprehensive protections in all indoor areas did not change significantly. Support for smoke-free bars is typically lower than support for other smoke-free locations (18-20), allowing more room for improvement. Where support was already high for smoke-free workplaces $(79.3 \%)$ and restaurants $(83.3 \%)$, achieving a significant increase in support would be more difficult.

An unexpected finding of the study was that the educational media campaigns had a markedly different effect on black residents than on white residents in changing knowledge about the dangers of SHS. Results comparing knowledge across time show that for black residents, beliefs about the dangers of SHS increased significantly for 4 of 6 knowledge questions, whereas for white residents, there were no significant increases. This finding is surprising, especially because belief in the dangers of SHS was already higher among black residents than white residents on almost all precampaign questions. Greater exposure to the campaign could help to explain this difference; we found that the proportion of black respondents who reported seeing a television advertisement was sig- nificantly higher than the proportion of white respondents. Further research may be needed to help explain the discrepancy in these knowledge changes and the potential role of educational media campaigns in targeting demographic groups.

Several limitations to this study should be noted. Our survey used unaided recall of television or radio advertisements as a measure to operationalize exposure to the educational media campaigns. Although this measure has the benefit of being conservative, it is strictly dichotomous and does not account for the effect of varying degrees of exposure to the campaign. Furthermore, we did not attempt to measure the independent effect of the 2 educational media campaigns; thus, findings reflect the effects of both the local and the national campaigns on Mobile County residents. On the basis of their focus group results, MCHD selected less aggressive, colorful advertisements with the principal goal of educating about the dangers of SHS and promoting the message that everyone has the right to breathe smoke-free air in enclosed public places. However, advertisements emphasizing the serious health effects of smoking on individuals are most effective at generating increased knowledge or positive beliefs (21). Therefore, although the Just Breathe campaign aimed primarily to educate about the dangers of SHS in an attempt to change attitudes regarding smoke-free environments, the Tips campaign likely supported MCHD's second campaign goal of focusing on key health effects of smoking.

Our findings coincide with recent research and evaluation $(9,10)$ suggesting that educational mass media campaigns have the potential to increase support for smoke-free environments. Our study supports the hypothesis that conducting educational media campaigns before the implementation of smoke-free protections can be an effective means of shifting attitudes in favor of these protections. One may infer from this study that among workplaces, restaurants, and bars, attitudes toward smoke-free bars may have the greatest likelihood for change, which is noteworthy, because support for smoke-free bars is typically lower than support for other smoke-free locations. These findings are important because they highlight the potential effects of a public health intervention that should be considered when communities are seeking sustainable, high-impact environmental changes to protect residents from the dangers of SHS. Future research and evaluation should explore the effect of different messages and educational media campaign approaches on knowledge of the dangers of SHS and support for smoke-free environments.

\section{Acknowledgments}

This article was supported in part by a cooperative agreement from CDC (\#1U58DP002401-01) to the Alabama Department of Public Health. Portions of this project's work involve the CPPW initiat-

The opinions expressed by authors contributing to this journal do not necessarily reflect the opinions of the U.S. Department of Health and Human Services, the Public Health Service, the Centers for Disease Control and Prevention, or the authors' affiliated institutions. 
ive supported by CDC funding. Users of this document should be aware that every funding source has different requirements governing the appropriate use of those funds. Under United States law, no federal funds are permitted to be used for lobbying or to influence, directly or indirectly, specific pieces of pending or proposed legislation at the federal, state, or local levels. Organizations should consult appropriate legal counsel to ensure compliance with all rules, regulations, and restriction of any funding sources.

We thank Kathleen Whitten and Janice Vick at ICF International for their contributions in reviewing and providing valuable feedback for this manuscript.

\section{Author Information}

Corresponding Author: Gabriel H. Fosson, MPA, Institute for Social Science Research, The University of Alabama, 306 Paul Bryant Dr E, Box 870216, Tuscaloosa, AL 35487. Telephone: 205-348-6233. E-mail: ghfosson@crimson.ua.edu. After publication of this article, correspondence should be sent to Debra M. McCallum, PhD, at the same address; telephone, 205-3483820; or e-mail,dmccallu@ua.edu.

Author Affiliations: Debra M. McCallum, Michael B. Conaway, The University of Alabama, Tuscaloosa, Alabama.

\section{References}

1. Farrelly MC, Healton CG, Davis KC, Messeri P, Hersey JC, Haviland ML. Getting to the truth: evaluating national tobacco countermarketing campaigns. Am J Public Health 2002; 92(6):901-7. Erratum in Am J Public Health 2003;93(5):703.

2. Hersey JC, Niederdeppe J, Evans WD, Nonnemaker J, Blahut $\mathrm{S}$, Farrelly $\mathrm{MC}$, et al. The effects of state counterindustry media campaigns on beliefs, attitudes, and smoking status among teens and young adults. Prev Med 2003;37(6 Pt 1):544-52.

3. Gagné L. The 2005 British Columbia smoking cessation mass media campaign and short-term changes in smokers attitudes. J Health Commun 2008;13(2):125-48.

4. Popham WJ, Potter LD, Hetrick MA, Muthén LK, Duerr JM, Johnson MD. Effectiveness of the California 1990-1991 tobacco education media campaign. Am J Prev Med 1994; 10(6):319-26.

5. Hu TW, Sung HY, Keeler TE. Reducing cigarette consumption in California: tobacco taxes vs an anti-smoking media campaign. Am J Public Health 1995;85(9):1218-22.
6. Hyland A, Wakefield M, Higbee C, Szczypka G, Cummings KM. Anti-tobacco television advertising and indicators of smoking cessation in adults: a cohort study. Health Educ Res 2006;21(3):348-54.

7. McAlister A, Morrison TC, Hu S, Meshack AF, Ramirez A, Gallion K, et al. Media and community campaign effects on adult tobacco use in Texas. J Health Commun 2004; 9(2):95-109.

8. Miller CL, Wakefield M, Roberts L. Uptake and effectiveness of the Australian telephone Quitline service in the context of a mass media campaign. Tob Control 2003;12(Suppl 2):ii53-8.

9. Alday J, Murukutla N, Cedillo C, Johns P, Monteiro A, Wakefield M. Smoke-free São Paulo: a campaign evaluation and the case for sustained mass media investment. Salud Publica Mex 2010;52(Suppl 2):S216-25.

10. Thrasher JF, Huang L, Pérez-Hernández R, Niederdeppe J, Arillo-Santillán E, Alday J. Evaluation of a social marketing campaign to support Mexico City's comprehensive smoke-free law. Am J Public Health 2011;101(2):328-35.

11. SMART: BRFSS city and county data. Atlanta (GA): Centers for Disease Control and Prevention, US Department of Health and Human Services. http://apps.nccd.cdc.gov/BRFSS$\begin{array}{llllll}\mathrm{S} & \mathrm{M} & \mathrm{A} & \mathrm{R} & \mathrm{T}\end{array}$ MMSARiskChart.asp?yr=2010\&MMSA=209\&cat=TU\&qkey $=4396 \&$ grp $=0$. Accessed July 8, 2014.

12. Prevalence and trends data, nationwide (states and DC) 2010, tobacco use. Atlanta (GA): Centers for Disease Control and Prevention, US Department of Health and Human Services. http://apps.nccd.cdc.gov/BRFS / display.asp? cat $=$ TU\&yr $=2010 \& q \mathrm{key}=4396 \&$ state $=U B$. Accessed July 8, 2014.

13. Bunnell R, O’Neil D, Soler R, Payne R, Giles WH, Collins J, et al. Fifty communities putting prevention to work: accelerating chronic disease prevention through policy, systems and environmental change. J Community Health 2012; 37(5):1081-90.

14. McAfee T, Davis KC, Alexander RLJr, Pechacek TF, Bunnell R. Effect of the first federally funded US antismoking national media campaign. Lancet 2013;382(9909):2003-11.

15. Starr G, Rogers T, Schooley M, Porter S, Wiesen E, Jamison N. Key outcome indicators for evaluating comprehensive tobacco control programs. Atlanta (GA): Centers for Disease Control and Prevention; 2005.

The opinions expressed by authors contributing to this journal do not necessarily reflect the opinions of the U.S. Department of Health and Human Services, the Public Health Service, the Centers for Disease Control and Prevention, or the authors' affiliated institutions. 
16. The American Association for Public Opinion Research. Standard definitions: final dispositions of case codes and outcome rates for surveys. 7th edition; 2011. http:// w $\quad$ w $\quad$ w Template.cfm?Section $=$ Standard_Definitions $2 \&$ Template $=/$ $\mathrm{CM} /$ ContentDisplay.cfm\&ContentID $=3156$. Accessed October 11, 2013.

17. Holm S. A simple sequentially rejective multiple test procedure. Scand J Stat 1979;6:65-70.

18. King BA, Dube SR, Tynan MA. Attitudes toward smoke-free workplaces, restaurants, and bars, casinos, and clubs among U.S. adults: findings from the 2009-2010 National Adult Tobacco Survey. Nicotine Tob Res 2013;15(8):1464-70.

19. Mons U, Nagelhout GE, Guignard R, McNeill A, van den Putte B, Willemsen MC, et al. Comprehensive smoke-free policies attract more support from smokers in Europe than partial policies. Eur J Public Health 2012;22(Suppl 1):10-6.

20. Maguire RL, Brinkley J, Mansfield C. Attitudes toward smoking restrictions in work sites, restaurants, and bars among North Carolinians. N C Med J 2010;71(6):511-8.

21. Durkin S, Brennan E, Wakefield M. Mass media campaigns to promote smoking cessation among adults: an integrative review. Tob Control 2012;21(2):127-38.

The opinions expressed by authors contributing to this journal do not necessarily reflect the opinions of the U.S. Department of Health and Human Services, the Public Health Service, the Centers for Disease Control and Prevention, or the authors' affiliated institutions. 


\section{Tables}

Table 1. Characteristics of Residents Surveyed Before or After (Cross-Sectional Design) an Educational Media Campaign ${ }^{a}$ About the Dangers of Secondhand Smoke Exposure, Mobile County, Alabama, 2011 and 2012 ${ }^{\mathrm{b}}$

\begin{tabular}{|c|c|c|c|c|c|}
\hline Characteristic & $\begin{array}{l}\text { Precampaign Unweighted } \\
\text { No. }(\%)(n=845)\end{array}$ & $\begin{array}{l}\text { Postcampaign Unweighted, } \\
\text { No. }(\%)(n=766)\end{array}$ & $\begin{array}{l}\text { Precampaign to } \\
\text { Postcampaign } \mathrm{X}^{2}\end{array}$ & $\begin{array}{c}P \\
\text { Value }\end{array}$ & $\begin{array}{l}\text { Weighted } \\
\% \mathrm{c}\end{array}$ \\
\hline \multicolumn{6}{|l|}{ Age, y } \\
\hline $18-24$ & $21(3)$ & $23(3)$ & \multirow{7}{*}{6.60} & \multirow{7}{*}{.36} & 13 \\
\hline $25-34$ & $54(6)$ & $50(7)$ & & & 17 \\
\hline $35-44$ & $74(9)$ & $84(11)$ & & & 17 \\
\hline $45-54$ & $149(18)$ & $139(18)$ & & & 20 \\
\hline $55-64$ & $233(28)$ & $171(23)$ & & & 16 \\
\hline $65-74$ & $178(21)$ & $163(21)$ & & & 10 \\
\hline$\geq 75$ & $131(16)$ & $129(17)$ & & & 8 \\
\hline \multicolumn{6}{|l|}{ Sex } \\
\hline Male & $265(31)$ & $253(33)$ & \multirow{2}{*}{0.44} & \multirow{2}{*}{.51} & 47 \\
\hline Female & $580(69)$ & $513(67)$ & & & 53 \\
\hline \multicolumn{6}{|l|}{ Race } \\
\hline White & $552(66)$ & $512(67)$ & \multirow{3}{*}{3.27} & \multirow{3}{*}{.19} & 64 \\
\hline Black & $249(30)$ & $228(30)$ & & & 32 \\
\hline Other & $40(5)$ & $22(3)$ & & & 4 \\
\hline \multicolumn{6}{|l|}{ Education } \\
\hline $\begin{array}{l}\text { Less than high school } \\
\text { graduate }\end{array}$ & $73(9)$ & $69(9)$ & \multirow{4}{*}{1.01} & \multirow{4}{*}{.80} & 18 \\
\hline High school graduate & $281(33)$ & $247(32)$ & & & 33 \\
\hline Some college & $246(29)$ & $240(31)$ & & & 31 \\
\hline $\begin{array}{l}\text { College graduate or } \\
\text { higher }\end{array}$ & $245(29)$ & $210(27)$ & & & 18 \\
\hline
\end{tabular}

a The precampaign survey was conducted August-October 2011, and the postcampaign survey was conducted June-September 2012.

b Numbers may not equal total $n$ because of missing data. Percentages may not total 100 because of rounding.

c Precampaign and postcampaign groups combined. 


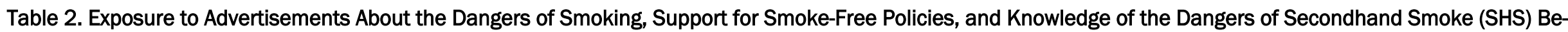
fore and After an Educational Media Campaign, Mobile County, Alabama, 2011 and 2012

\begin{tabular}{|c|c|c|c|c|c|c|c|c|c|}
\hline \multirow[b]{2}{*}{ Survey Question } & \multicolumn{3}{|c|}{ Black, \% } & \multicolumn{3}{|c|}{ White, \% } & \multicolumn{3}{|c|}{ Total, \%a } \\
\hline & $\begin{array}{l}\text { Precampaign } \\
(n=249)\end{array}$ & $\begin{array}{l}\text { Postcampaign } \\
(n=228)\end{array}$ & $\begin{array}{c}P \\
\text { Value }^{\mathrm{b}}\end{array}$ & $\begin{array}{l}\text { Precampaign } \\
\quad(n=552)\end{array}$ & $\begin{array}{l}\text { Postcampaign } \\
(n=512)\end{array}$ & $\begin{array}{c}P \\
\text { Value }^{\mathrm{b}}\end{array}$ & $\begin{array}{l}\text { Precampaign } \\
(n=845)\end{array}$ & $\begin{array}{l}\text { Postcampaign } \\
(n=766)\end{array}$ & $\begin{array}{c}P \\
\text { Value }^{\text {b }}\end{array}$ \\
\hline
\end{tabular}

Media exposure - In the past 30 days. . .

\begin{tabular}{|c|c|c|c|c|c|c|c|c|c|}
\hline . . . saw a TV advertisement & 62.6 & 86.5 & $<.001$ & 52.3 & 77.7 & $<.001$ & 55.8 & 80.9 & $<.001$ \\
\hline ... heard a radio advertisement & 25.7 & 34.0 & .08 & 23.6 & 29.1 & .06 & 24.8 & 29.9 & .09 \\
\hline . . . saw a billboard & 40.7 & 47.8 & .11 & 35.7 & 49.0 & $<.001$ & 36.8 & 49.0 & $<.001$ \\
\hline $\begin{array}{l}\text {.. s saw a newspaper or print } \\
\text { advertisement }\end{array}$ & 27.5 & 19.2 & .03 & 22.1 & 23.2 & .76 & 23.8 & 23.0 & .74 \\
\hline
\end{tabular}

\section{Support for smoke-free policies}

\begin{tabular}{|c|c|c|c|c|c|c|c|c|c|}
\hline Workplaces & 80.3 & 81.6 & .92 & 78.1 & 84.0 & .16 & 79.3 & 83.0 & .37 \\
\hline Restaurants & 83.2 & 89.0 & .04 & 82.6 & 83.2 & .82 & 83.3 & 83.6 & .92 \\
\hline Bars & 40.9 & 49.2 & .18 & 34.2 & 41.4 & .02 & 38.1 & 43.8 & .01 \\
\hline $\begin{array}{l}\text { Comprehensive protections for all } \\
\text { public indoor areas }\end{array}$ & 72.1 & 78.3 & .23 & 70.8 & 70.5 & .69 & 72.0 & 71.9 & .56 \\
\hline Believe SHS is very harmfulc & 71.1 & 86.5 & $<.001$ & 61.8 & 61.7 & $>.99$ & 65.8 & 71.0 & .03 \\
\hline \multicolumn{10}{|l|}{ Believe SHS causes ... . } \\
\hline ... lung cancer in adults & 84.7 & 93.9 & $<.001$ & 80.7 & 78.5 & .63 & 82.2 & 84.1 & .91 \\
\hline ... heart disease in adults & 75.8 & 84.8 & .01 & 69.1 & 75.0 & .40 & 71.2 & 78.5 & $<.001$ \\
\hline ... colon cancer in adults & 36.8 & 41.0 & .07 & 24.3 & 18.9 & .09 & 27.9 & 27.5 & .31 \\
\hline ... respiratory problems in children & 91.4 & 98.4 & $<.001$ & 90.2 & 92.0 & .68 & 90.8 & 94.3 & .02 \\
\hline ... sudden infant death syndrome & 44.6 & 55.1 & .03 & 31.3 & 29.3 & .67 & 36.3 & 38.9 & .30 \\
\hline
\end{tabular}

a Includes all respondents, regardless of racial group.

${ }^{b} x^{2}$ test of the difference between precampaign and postcampaign.

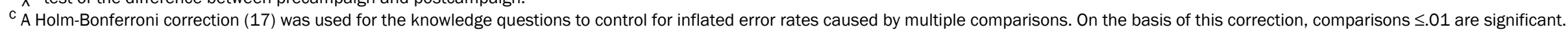

The opinions expressed by authors contributing to this journal do not necessarily reflect the opinions of the U.S. Department of Health and Human Services, the Public Health Service, the Centers for Disease Control and Prevention, or the authors' affiliated institutions. 
Table 3. Effect of Exposure to an Educational Media Campaign on Support for Smoke-Free Policies and Knowledge of the Dangers of Secondhand Smoke (SHS) Exposure, Mobile County, Alabama, 2012

\begin{tabular}{|c|c|c|c|c|c|}
\hline \multirow[b]{2}{*}{ Dependent Variable } & \multicolumn{2}{|c|}{ No Campaign Exposure } & \multicolumn{3}{|c|}{ Campaign Exposure } \\
\hline & $\%$ & OR & $\%$ & OR $(95 \% \mathrm{Cl})$ & $P$ Value \\
\hline \multicolumn{6}{|l|}{ Support for smoke-free policies } \\
\hline Workplaces & 79.2 & 1 [Reference] & 86.5 & $1.9(1.2-2.8)$ & .008 \\
\hline Restaurants & 77.8 & 1 [Reference] & 88.4 & $1.9(1.2-2.9)$ & .006 \\
\hline Bars & 38.5 & 1 [Reference] & 48.2 & $1.5(1.1-2.0)$ & .013 \\
\hline Comprehensive protections for all public indoor areas & 68.4 & 1 [Reference] & 74.9 & $1.2(0.9-1.8)$ & .25 \\
\hline Believe SHS is very harmful & 69.0 & 1 [Reference] & 72.5 & $1.3(0.9-1.8)$ & .22 \\
\hline \multicolumn{6}{|l|}{ Believe SHS causes ... } \\
\hline ... lung cancer in adults & 83.2 & 1 [Reference] & 84.8 & $1.1(0.7-1.8)$ & .53 \\
\hline ... heart disease in adults & 76.9 & 1 [Reference] & 79.8 & $1.4(0.9-2.0)$ & .10 \\
\hline ... colon cancer in adults & 28.5 & 1 [Reference] & 26.6 & $1.1(0.7-1.5)$ & .80 \\
\hline ... respiratory problems in children & 92.6 & 1 [Reference] & 95.7 & $1.9(1.0-3.7)$ & .06 \\
\hline ... sudden infant death syndrome & 39.9 & 1 [Reference] & 38.1 & $0.9(0.6-1.2)$ & .45 \\
\hline
\end{tabular}

Abbreviations: OR, odds ratio; $\mathrm{Cl}$, confidence interval.

a Controlling for smoking status, sex, race, and education. The ORs and $P$ values were calculated using multivariate logistic regression. 